\title{
Vector-borne helminths of dogs and humans in Europe
}

\author{
Domenico Otranto ${ }^{1 *}$, Filipe Dantas-Torres ${ }^{1,2}$, Emanuele Brianti ${ }^{3}$, Donato Traversa ${ }^{4}$, Dusan Petric ${ }^{5}$, \\ Claudio Genchi ${ }^{6}$ and Gioia Capelli ${ }^{7}$
}

\begin{abstract}
Presently, $45 \%$ of the total human population of Europe, as well as their domestic and companion animals, are exposed to the risk of vector-borne helminths (VBH) causing diseases. A plethora of intrinsic biological and extrinsic factors affect the relationship among helminths, vectors and animal hosts, in a constantly changing environment. Although canine dirofilarioses by Dirofilaria immitis and Dirofilaria repens are key examples of the success of VBH spreading into non-endemic areas, another example is represented by Thelazia callipaeda eyeworm, an emergent pathogen of dogs, cats and humans in several regions of Europe. The recent finding of Onchocerca lupi causing canine and human infestation in Europe and overseas renders the picture of VBH even more complicated. Similarly, tick-transmitted filarioids of the genus Cercopithifilaria infesting the skin of dogs were recently shown to be widespread in Europe. Although for most of the VBH above there is an increasing accumulation of research data on their distribution at national level, the overall impact of the diseases they cause in dogs and humans is not fully recognised in many aspects. This review investigates the reasons underlying the increasing trend in distribution of VBH in Europe and discusses the diagnostic and control strategies currently available. In addition, this article provides the authors' opinion on some topics related to VBH that would deserve further scientific investigation.
\end{abstract}

Keywords: Zoonosis, Dirofilaria immitis, Dirofilaria repens, Onchocerca lupi, Cercopithifilaria, Thelazia callipaeda, Europe, Risk, Mosquito, Tick, Vector, Treatment, Control

\section{Introduction}

A large number of vector-borne helminths (VBH) are prevalent in Europe, and some of them are of growing importance due to the significant level of disease they cause in dogs and humans [1-3]. Presently, $45 \%$ of the total human population of Europe, as well as their domestic and companion animals, are exposed to the risk of $\mathrm{VBH}$ [4]. A complex range of intrinsic biological factors (e.g., vectorial capacity, biting rates), extrinsic and environmental factors (e.g., climate, population movements and trade), affects the interactions between parasitic helminths, vectors and animals, including humans, rendering investigations on VBH a complex task. Indeed, the spreading process of VBH in previously non-endemic geographical areas has been primarily associated with the

\footnotetext{
* Correspondence: domenico.otranto@uniba.it

'Dipartimento di Medicina Veterinaria, Università degli Studi di Bari, Bari, Valenzano, Italy

Full list of author information is available at the end of the article
}

biology and ecology of the arthropod vectors and their capability to establish transmission cycles, maintaining the infestation in populations of susceptible hosts. Since the beginning of the millennium, many vectors have been introduced into Europe as a consequence of human demographics (e.g., the growth of cities), international movement of people (travellers and refugees), the smuggling of wildlife, the trade of animals and goods, such as used tires and ornamental plants [5]. For example, human activities have initiated the spread of invasive mosquito species and vector-borne diseases, and on-going globalization and increases in mean temperature may greatly extend the magnitude of this process [4].

The present article is focused on major VBH infesting dogs and humans. Among this diverse group of pathogens, Dirofilaria immitis and Dirofilaria repens (Spirurida, Onchocercidae) are probably the best known. Indeed, D. immitis has a severe impact on veterinary medicine, because of the heartworm disease

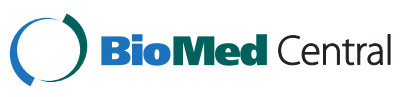


threatening dogs and cats, whereas D. repens, causing subcutaneous infestation in dogs, is the main agent of human dirofilariosis. Although Dirofilaria spp. above represent key examples of the success of this group of parasites in spreading into non-endemic areas, over the last ten years other zoonotic helminths, such as Thelazia callipaeda eyeworm (Spirurida, Thelaziidae) have been accounted as emergent VBH of animals and humans in several Europe regions [5]. In addition, the puzzle become even more complicated to solve by the recent finding of a little known filarioid of dogs, i.e. Onchocerca lupi (Spirurida, Onchocercidae), which causes canine and human infestation in Europe and overseas. This nematode primarily induces nodular lesions under the conjunctiva and sclera of dogs and its biology and actual distribution remain for many aspects unknown to science. Adults of the less known Acanthocheilonema reconditum and Acanthocheilonema dracunculoides are beneath the subcutaneous tissues of the limbs and back of dogs. Recently, tick-transmitted filarioids of the genus Cercopithifilaria infesting the skin of dogs were shown to be surprisingly distributed in canine populations of Europe [6].

Although for many of the VBH above there is an increasing accumulation of information about their distribution at national level, the overall impact of diseases they cause in dogs and humans is not fully recognised in many aspects. This review aims at investigating the main reasons underlying the increasing trend in distribution of the most important VBH in Europe and to discuss the diagnostic and control strategies currently available. In addition, this article provides the authors' opinion on some topics related to $\mathrm{VBH}$ that would deserve further scientific investigation.

\section{Review}

Old and emerging VBH of dogs and humans in Europe

Dirofilarioses caused by filarioid nematodes of the genus Dirofilaria are transmitted at their third larval stage by bloodsucking mosquitoes primarily to dogs, although cases of human dirofilariosis are increasingly reported [1]. Adult D. immitis worms occur in the pulmonary arteries and right heart chambers, causing a severe condition, known as canine and feline heartworm disease, while $D$. repens is found mainly in subcutaneous tissues, causing subcutaneous dirofilariosis. Dirofilaria nematodes develop throughout five larval stages within the intermediate vector mosquito host (from embryo to infective L3 larva), and in the definitive vertebrate host (from L3 to the adult stage). The adult females of $D$. immitis and D. repens develop in 120-180 and 189-259 days, respectively, and release microfilariae into the blood of the definitive host [7]. The intermediate hosts are mosquitoes of the family Culicidae (e.g. Anopheles, Aedimorphus, Armigeres,
Ochlerotatus, Stegomyia, Culex, Coquillettidia and Mansonia), with Aedimorphus vexans [Aedes vexans], Culex pipiens pipiens (Figure 1) and Stegomyia albopicta [Ae. albopictus] (Figure 2) being implicated as the main vectors of these worms in Europe [8]. Dirofilaria repens is able to grow under laboratory conditions in the same mosquito species and at the same temperature and humidity as D. immitis, with similar developmental time, from the microfilarial stage to the infective larva [7].

Acanthocheilonema reconditum has a global distribution and, in many geographical areas of the Mediterranean Basin (Figure 3), Middle East, South Africa, South America and Oceania, it is the sole or the most prevalent filarioid species, infesting dogs [9]. Differently from other filarioids transmitted by mosquitoes (e.g., D. immitis and D. repens) or ticks (e.g., Cercopithifilaria spp.) to dogs, A. reconditum completes its life cycle in and is vectored by fleas (i.e., Ctenocephalides canis, Ctenocephalides felis, Pulex irritans, Pulex simulans, Echidnophaga gallinae) or lice (i.e., Heterodoxus spiniger, Linognathus setosus) with a rate of infestation in fleas of about 5\% [9].

Over the last 20 years, $T$. callipaeda has been repeatedly reported to infest the conjunctival sac of domestic (dogs and cats) and wild carnivores (e.g., foxes, wolves, beech martens and wild cats) in Europe [10]. Nowadays, this nematode is recognised as endemic in many European countries (Figure 3) such as France [11,12], Switzerland [13], Spain [14] and Portugal [15] at the similar latitude range (between $39^{\circ}$ and $46^{\circ} \mathrm{N}$ ) than those of Asia (between $10^{\circ}$ and $45^{\circ} \mathrm{N}$ for India and Japan, respectively) where the infestation seemed to be confined [16]. Indeed, for its geographical distribution (i.e., in the former Soviet Republics and in many far eastern countries including India, Thailand, China and Japan), this nematode has been known for a long time as "oriental eye-worm" [17].

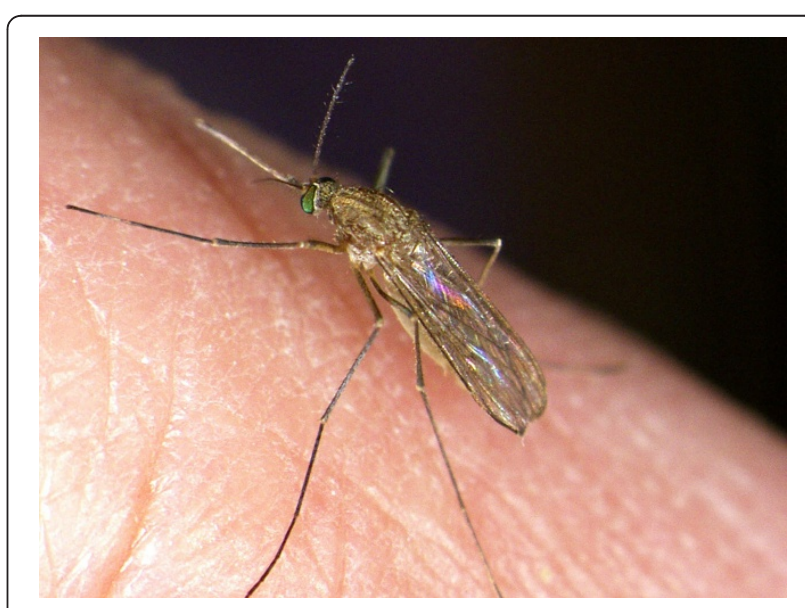

Figure 1 Culex pipiens pipiens. Culex pipiens pipiens feeding on a human host (Courtesy of Fabrizio Montarsi). 


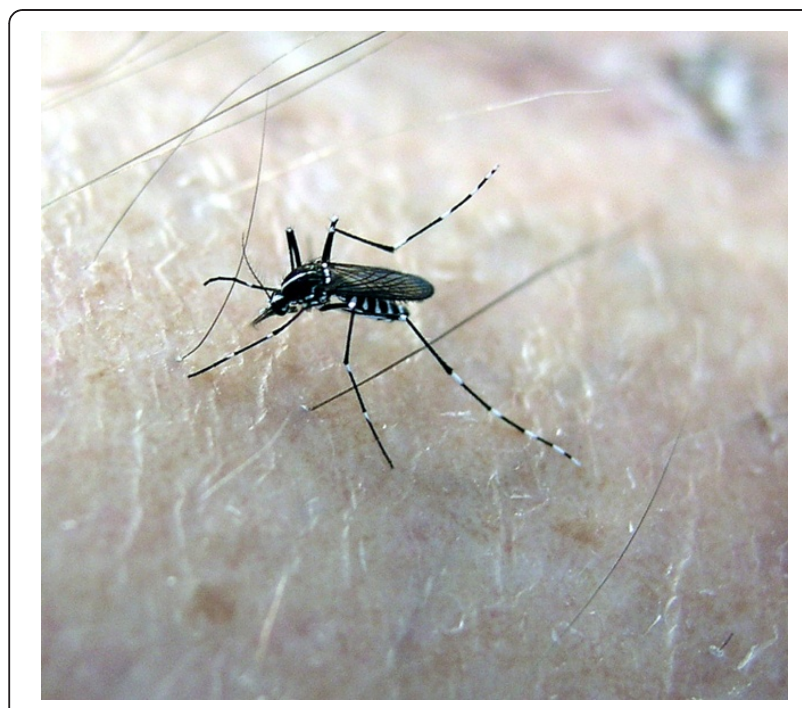

Figure 2 Stegomyia albopicta. Stegomyia albopicta feeding on a human host (Courtesy of Nediljko Landeka).

Since the first evidence of its development in a "bizarre" drosophilid vector, Phortica variegata (Diptera, Drosophilidae, Steganinae) $[18,19]$, the occurrence of this helminth seems to be on the rise, probably also due to the improved awareness of parasitologists and practitioners. Interestingly, cases of human thelaziosis in Europe have been diagnosed in north-western Italy, south-eastern France [20] and Spain [21].

Onchocerca lupi is an even less known VBH parasitizing the periocular tissues of dogs and cats which has been recognised as a valid species on morphological and molecular grounds [22]. This parasite has been found to infect dogs in southern (Greece, Portugal) and Central Europe (Germany, Hungary, Portugal, Switzerland) [23-27] (Figure 3) and the United States [28-30] where it was recently found also in cats [31]. It causes acute or chronic ocular disease, characterized by conjunctivitis, photophobia, lacrimation, ocular discharge and exophthalmia [32]. Unfortunately, the role played by dogs as reservoirs of $O$. lupi deserves to be assessed and knowledge on the biological vector of this infestation remains meagre [33].

A group of rather neglected filarioids belonging to the genus Cercopithifilaria parasitizing the skin of a range of host species [34] has also been recently studied in dogs [35] and three species (namely Cercopithifilaria sp.1, Cercopithifilaria sp.2 and Cercopithifilaria grassii) have been morphologically and molecularly differentiated [36]. In addition, for Cercopithifilaria sp.1, the competence of the brown dog tick, Rhipicephalus sanguineus, as intermediate host has been experimentally demonstrated [37] and field evidence supports their role as vectors of this filarioid [6]. Following the first retrieval of Cercopithifilaria sp.1 from a dog from Sicily, Italy, this filarioid was diagnosed in dogs from Spain, Greece and southern Italy (i.e., Apulia, Basilicata and Sicily regions) (Figure 3), with prevalence rates reaching up to $21.6 \%$ [6]. While their pathogenicity to humans is unlikely, there is some evidence indicating the occurrence of skin alterations associated to the presence of larvae in the dermis of dogs [38].

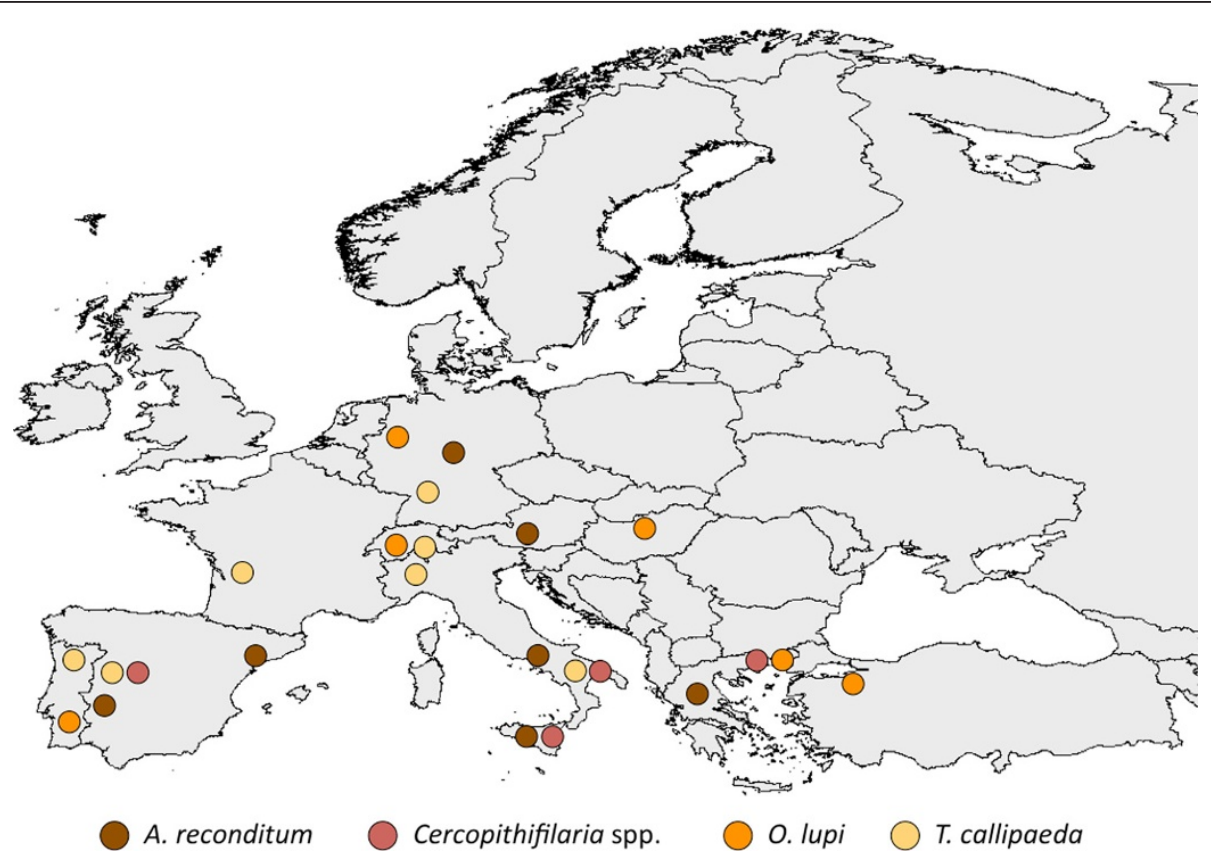

Figure 3 Distribution of Acanthocheilonema reconditum, Cercopithifilaria spp., Onchocerca lupi and Thelazia callipaeda in Europe. Map of Europe showing the distribution of Acanthocheilonema reconditum, Cercopithifilaria sp.1, Onchocerca lupi and Thelazia callipaeda. 
The role of vectors of $\mathrm{VBH}$ in a changing environment The dissemination of VBH in Europe has been primarily attributed to rapid geographic expansion of their vectors (e.g., invasive mosquitoes, zoophilic fruit flies) and/or increases in their population density. This results from the interaction of several factors, such as the availability of suitable hosts, the arthropod's adaptability to different environmental conditions, its feeding behaviour and host preferences [39-41]. There have also been extensive debates on the effects of climate change in Europe [42,43], since warmer climates could favour mosquito breeding and, along with higher air temperatures, shorten their extrinsic incubation periods as demonstrated for Stegomyia aegypti [Ae. aegypti] [44]. Indeed, projected increment in temperature will impact on insect vectors through broadening areas of colonization, invasion of new sites and, eventually, resulting in physiological changes and increased vector capacity. For example, climate change (e.g., increase in mean temperatures) has affected the mosquito abundance and their seasonal survival in many areas of Europe greatly impacting on the spread of filarial infestation [7]. Growing degree-day models (GDD), using wide or local scale temperature data, predicted the occurrence and seasonality of Dirofilaria spp. in different parts of the world. These models were based on the minimum threshold of $14^{\circ} \mathrm{C}$ for the development of Dirofilaria in their vector, the requirement of 130 GDD for larvae to reach infectivity and a maximum life expectancy of 30 days for a vector mosquito [7]. Therefore, it was predicted that, due to global warming and raising of mean temperatures, most of the European countries will be suitable for Dirofilaria transmission, with a lengthening in the duration of the filarial transmission season [7].

In addition, several intrinsic factors linked to the specific mosquito vector species also impact on the distribution of VBH. For example, based on retrospective evidence, the expansion of dirofilariosis in Europe somehow matched the second introduction of St. albopicta (in 1990 in Italy) [45] but it was not before 2000-2002, when both D. immitis and $D$. repens were found in natural populations of Asian tiger mosquito in Italy [46]. Accordingly, the rapid spread of this vector species throughout the country likely broadened the dirofilariosis range to southern regions not previously infected [47] (Figure 4), although the same areas were inhabited by $C x . p$. pipiens, which is considered the main vector of both Dirofilaria in Europe. The sympatric occurrence of both vectors, having diurnal and nocturnal biting activities, may enhance the risk of infestation to dogs and humans, thus increasing the vector-host contact and, eventually, the number of vectors which may carry filarioids in endemic areas throughout the day. Interestingly, over the past decades, $C x$. $p$. pipiens has changed its endophagic and antropophagic behaviour in Central and North Europe [4] where actually it also searches for human blood outdoors, as it happens in southern parts of the continent. This pattern also overlaps with the spread of canine $D$. immitis and $D$. repens infestation in central and north-eastern countries (e.g. south of Switzerland, Czech Republic, Hungary, Serbia and Slovak Republic) [7,48-52] (Figures 5,6).

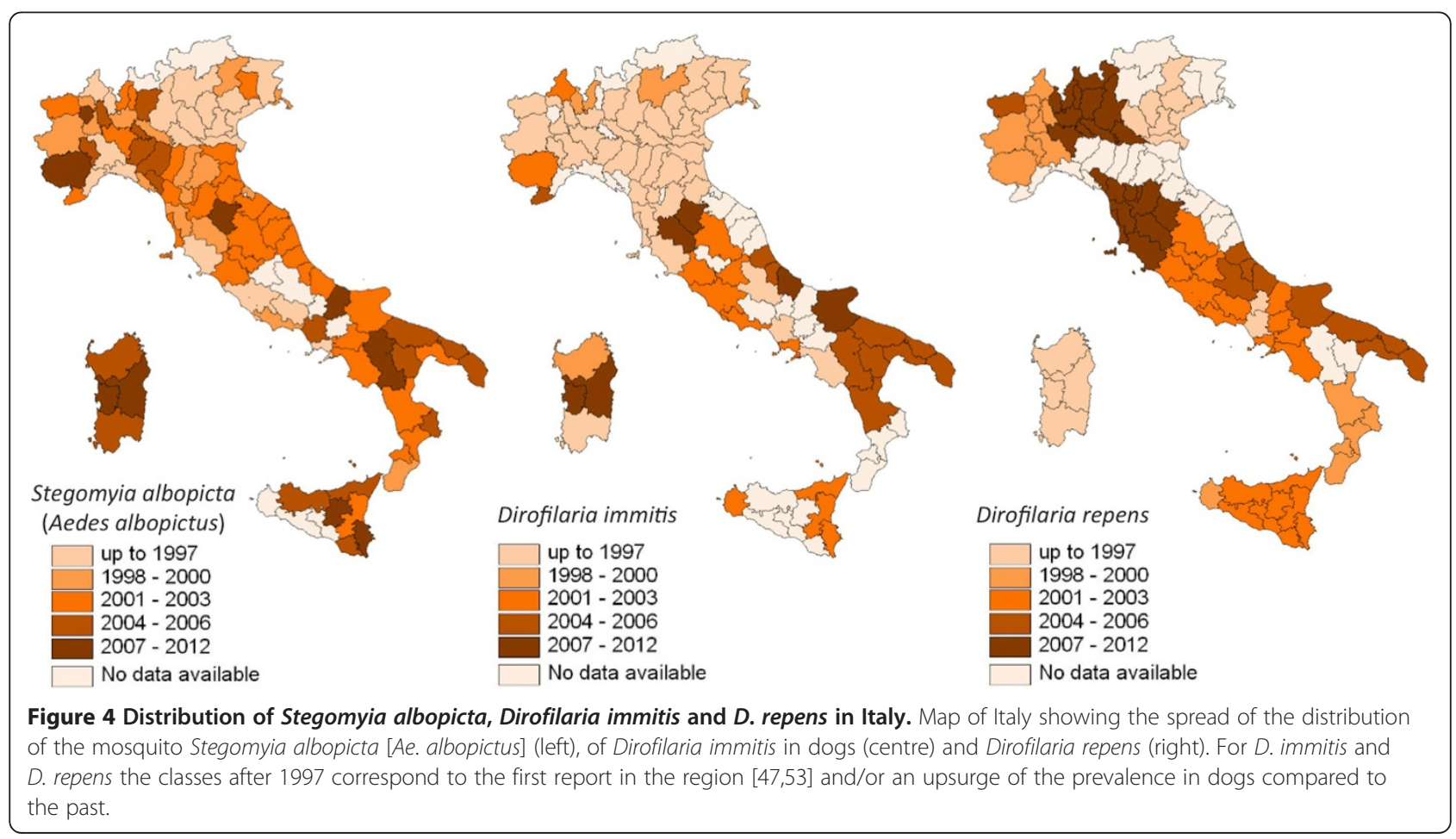




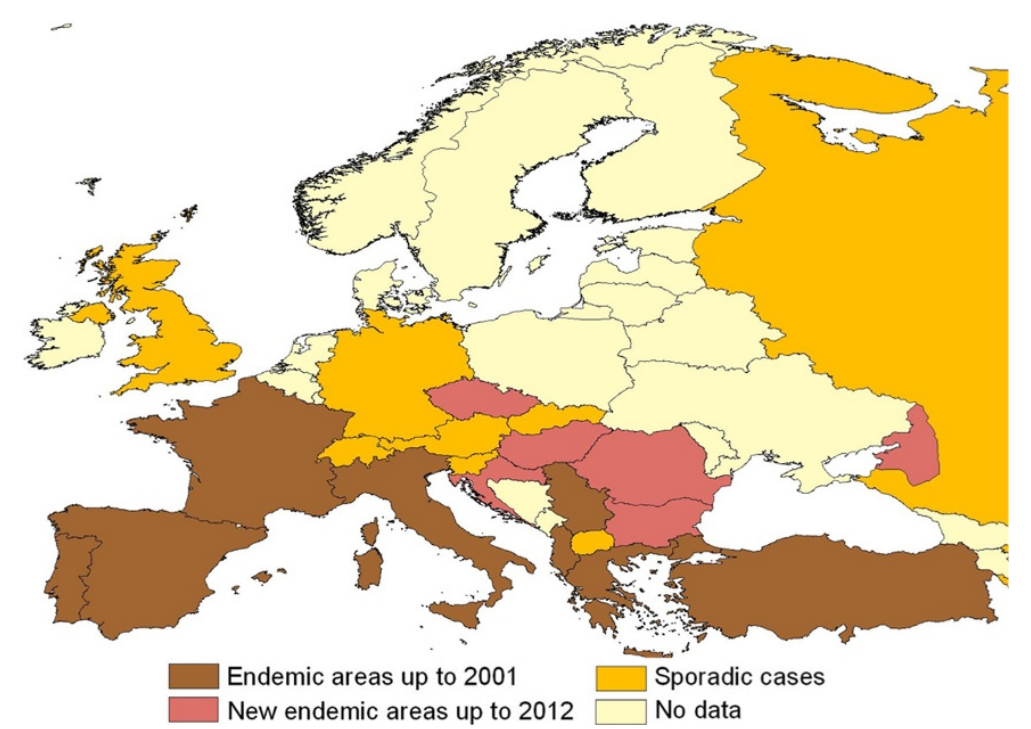

Figure 5 Dirofilaria immitis in Europe. Distribution of Dirofilaria immitis in dogs up to 2001 and later on. Modified from [3].

Black flies may play a role in the transmission of $O$. lupi in dogs and humans, no convincing scientific evidence in this regard has been produced so far [33]. One of the suspected vectors of $O$. lupi, Simulium reptans, is present in areas where the cases of dog ocular onchocerciasis have also been reported (i.e., Portugal, Switzerland, Germany and Hungary) [33]. Until about 50 years ago, S. reptans was the dominant black fly in the middle part of Danube valley, whereas today it is extremely rare in this area and it moved southwards down into the Balkan Peninsula [54]. However, in addition biting midges (Diptera, Ceratopogonidae) feeding on a wide range of hosts (humans, livestock and other mammals, amphibians, and birds) might be implicated in the transmission of $O$. lupi since some species of Culicoides have been involved in transmission of Onchocerca cervicalis and Onchocerca gutturosa to horses and cattle, respectively, in Europe [55].

In recent years, the use of the Geographic Information System (GIS) and predictive model algorithms provided important practical contributions to the investigation of the spatial component of the epidemiology of infectious diseases [56], including vector-borne diseases $[57,58]$. Moreover, the collection of georeferenced epidemiological data can also be useful for disease cluster identification and geostatistical analyses. For example, regional climate model scenarios coupled with high-resolution

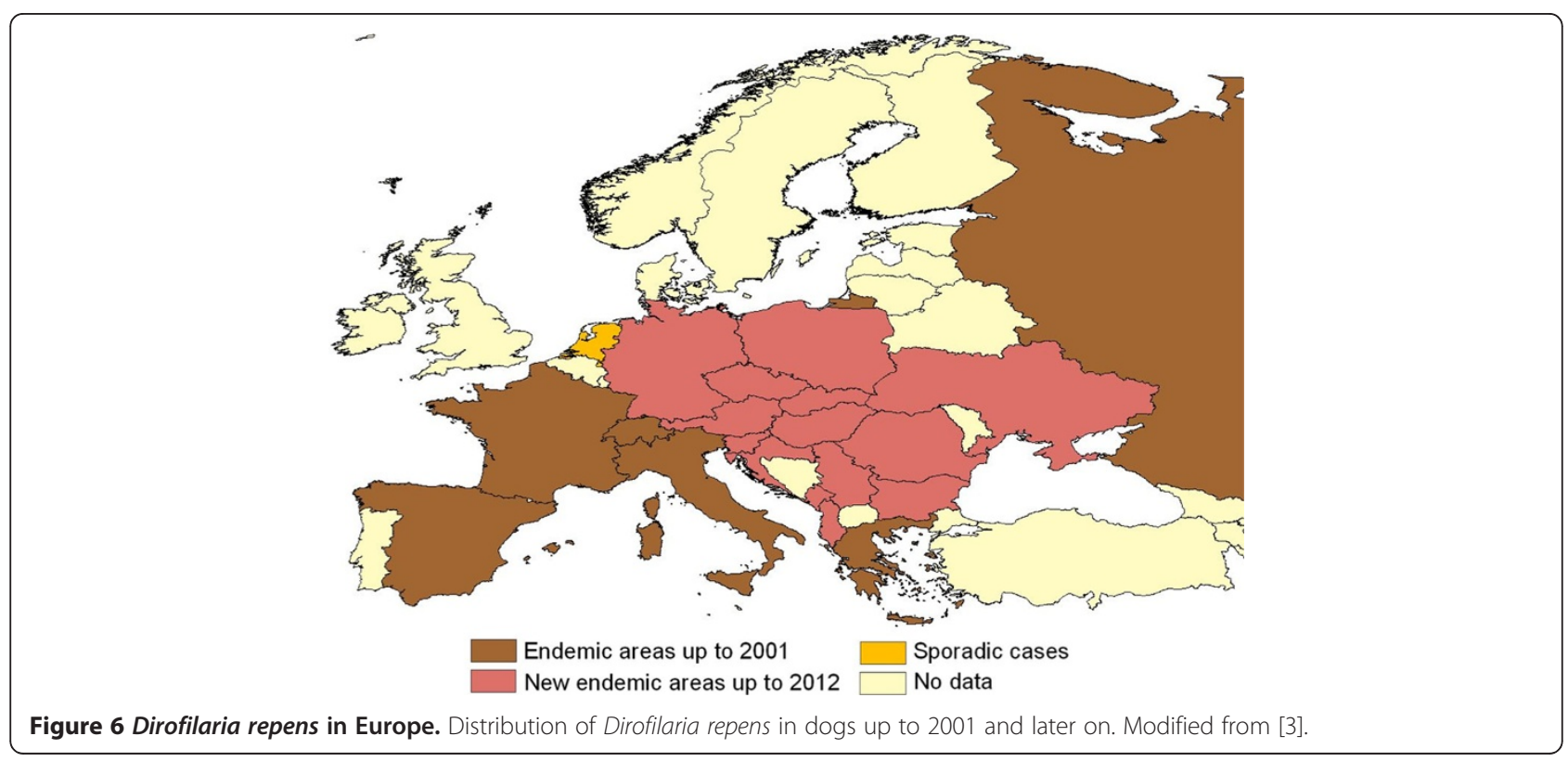


observations shows that during the 1960-1980s southern France, northern Italy, the northern coast of Spain, the eastern coast of the Adriatic Sea and western Turkey were climatically suitable areas for the establishment of the invasive Asian tiger mosquito, St. albopicta. Over the last two decades, climate conditions have become more suitable for the Asian tiger mosquito over Benelux, western Germany and the Balkans, while they have become less suitable over southern Spain. Similar trends are likely to be observed in the future, with an increased risk simulated over northern Europe and slightly decreased risk over southern Europe where drier and warmer summers might limit southward expansion of this species [59]. At the same time, six more indigenous mosquito species, Culex theileri [60], Anopheles maculipennis sensu lato, Coquillettidia richiardii [61], Aedimorphus vexans, Dahliana geniculata [Aedes geniculatus] and Ochlerotatus caspius [62-64] have recently been found infected by $D$. immitis in nature. All of the potential indigenous vectors are highly mammophylic and anthropophylic (excluding some members of $A n$. maculipennis complex and $C x$. theileri that only occasionally feed on humans) and could increase transmission rate of these filarioids.

Phortica variegata, the vector of $T$. callipaeda, was studied in an area of Italy where dog thelaziosis is highly prevalent [16] and found to be more active at $20-25^{\circ} \mathrm{C}$ and $50-75 \% \mathrm{RH}$ during July-August in southern Italy [19]. Suitable environments for the geographic distribution and development of $P$. variegata across Italy and Europe were predicted using a desktop implementation of the Genetic Algorithm for Rule-Set Prediction and all recent reports of $T$. callipaeda fall within the suitable areas indicated by the model $[12,14,15,65]$. Based on this model, the number of reports of $T$. callipaeda infestation may be expected to increase over the next years in areas where it is now considered as non-endemic.

\section{Host-vector interactions}

The availability of suitable hosts for a given $\mathrm{VBH}$ and the vector's feeding behaviour are among the most important factors impacting on VBH distribution. For example, domestic dogs are excellent reservoirs of filarioids, being able to survive for a long time with a considerable worm burden, to harbour different species of filarioids at the same time and to provide infectious microfilariae for competent vectors all over their season of activity. Indeed, among filarioids only D. immitis can cause a fatal and severe disease, but presently the majority of dogs harbour a low-medium burden of nematodes, and they show a few symptoms with chronic progression in almost all the cases [66]. Without a doubt, in order to act as good reservoirs of VBH dogs also need to be attractive for competent mosquito vectors as well as tolerant to mosquito bites. For example, in a heartworm endemic north-eastern area of Italy, 70\% of Cx. p. pipiens and $90 \%$ of Oc. caspius collected using dog-baited traps from June to September were engorged [67] and it was shown that the number of bites/dog/night can vary according to the vector density, weather conditions and dog size (average of 32.4 and maximum of 81 bites/dog/night). However, the attractiveness and tolerance to mosquitoes of other mammalian species should be considered when studying the potential reservoirs for filarioids in nature. Indeed, dogs are significantly more attractive to eight species of mosquitos (Aedimorphus taeniorhynchus [Aedes taeniorhynchus], Culex pipiens quinquefasciatus, An. maculipennis, Oc. caspius, Culiseta annulata, Ochlerotatus scapularis, Culex declarator and $C x . p$. pipiens) than cats $[68,69]$. In spite of this, cats are not good reservoirs for $D$. immitis, mainly due to host resistance, as inferred by the low adult worm burden in natural and experimental infections, the long prepatent period (8 months), the low level and short duration of microfilaraemia and life span of adult worms (2-3 years) in this host species [70]. Interestingly, some species or strains of mosquitoes displayed inherent mechanisms of defence (refractoriness) to infestation such as the ability of the cibarial armature to destroy microfilariae, the anticoagulant activity of mosquito salivary proteins on the bolus containing microfilariae and other arthropod immunological responses to larvae [71].

Prevalence of microfilaraemic dogs and presence and abundance of competent vectors also affect the rate of infestation within a given mosquito population, which, in turn, is directly related to the risk for a native dog to be infested. In an endemic area of north-eastern Italy out of 40,000 culicids captured from May to October, and screened for $D$. immitis and $D$. repens with a realtime polymerase chain reaction (PCR), $C x . p$. pipiens, Oc. caspius and Am. vexans were found positive for $D$. immitis with an estimated rate of infestation ranging from 0.21 to $1.11 \%$, according to date and site [64]. In the same study, $D$. repens was found in $C x$. p pipiens only (rate of infestation of $0.23-0.71 \%$ ). Interestingly, the rate of infestations did not vary significantly according to season, indicating that in spring a certain number of dogs may be ready to act as reservoirs and thus needing prolonged preventive treatments. In Turkey, an infestation rate of $0.41 \%$ and of $0.12 \%$ was recorded in Am. vexans, the main vector of $D$. immitis in this area, and in Cx. p. pipiens, respectively [63]. By combining the rate of infestations with the bites/dog/night numbers above for $C x . p$. pipiens in north-eastern Italy, it can be speculated that a dog living in an endemic area has a chance to encounter an infected mosquito every 6 nights during the low abundance mosquito period and every 1.2 nights during the high abundance period of the summer. For sure, this calculation does not take into account the presence 
and the abundance of St. albopicta, which is now established in many areas of southern Europe throughout the year [72]. Stegomyia albopicta, a vector of D. immitis $[46,73]$ and of $D$. repens [74] is active throughout the whole day and year in southern areas, especially in urban habitats. This scenario might be further complicated in the future by the introduction of new invasive mosquito species, such as Hulecoeteomyia koreica [Aedes koreicus], which is a potential vector of D. immitis in Belgium [75] and north-eastern Italy [76]. This species is colonizing colder environments, therefore increasing the possibility to enlarge the area at risk for dirofilariosis in Europe. The factors enhancing the exposure of the host to the vector (i.e., the dog's size, the age and the outside habitation) may further increase the risk of $D$. immitis infestation $[66,77]$. Other variables that are reported as risk factors, such as the sex, the length of the coat and dog's activities (i.e., guard, hunting, stray dogs vs. pet dogs) are likely to be biased by confounding factors, such as male dogs that are used as guard dogs and kept outside day and night.

In Europe, cats were found infected by D. immitis mainly in Italy, France and Portugal [3]. In Italy, the prevalence of feline heartworm disease has been approximately estimated as high as $10 \%$ of the known prevalence of the infestation in dogs [70]. However, filarioid infestation in cats can occur also in low endemic areas, as reported in central Italy [78]. Due to the very low worm burden usually found in cats, these animals are regarded as "victims" rather than reservoir of Dirofilaria spp. On the contrary, red foxes (Vulpes vulpes) were found infected by $D$. immitis in Italy, Spain and Bulgaria [3], with prevalence up to $32 \%$ in irrigated areas of Spain [79]. In Italy, out of 132 red foxes examined, 25\% harboured microfilariae of $D$. immitis, $0.7 \%$ of $D$. repens, $15 \%$ of $A$. reconditum and $2.3 \%$ of $A$. dracunculoides [80]. Other hosts found infected with $D$. immitis are wolves (Canis lupus), in Belarus, Italy and Spain [48,81], jackals (Canis aureus) in Bulgaria [82] and otters (Lutra lutra) in Portugal and Spain [83]. The first European record of D. immitis in ferrets (Mustela putorius putorius) has also been reported [84], with a particular and aberrant larval migration to the central nervous system. All these hosts are likely to represent an epi-phenomenon of dog infection, with the exception of red foxes, which may act as a wild reservoir of the infection.

In the case of $T$. callipaeda, the reasons underlying the steady spread of this nematode throughout many European countries are not clearly understood, but it seems that the same zoonotic strain of $T$. callipaeda circulates in the continent within different animal species and humans [18]. The occurrence of very high prevalence of thelaziosis by $T$. callipaeda in foxes $(49.3 \%)$ as well as in other wild carnivore species (i.e., wolves, beech martens, brown hares, and wild cats) in some areas of southern Italy where canine thelaziosis is highly prevalent (i.e., about $60 \%$ of dogs) indicates the status of hyper-endemicity of eyeworm infestation in this area and the primary role foxes play as reservoirs of the infestation [10]. The seasonality and crepuscular activity of $P$. variegata nicely overlaps the behaviour of those wild species hosts. The aforementioned ecological considerations are supported by molecular data on the occurrence of a single haplotype (i.e., h1) of $T$. callipaeda among different host species in the study area [18]. The same h1 was found in other European countries, irrespective of the host species from which they were collected [18]. These molecular findings and studies on P. variegata indicate a high level of affinity of the nematode for its vector $[18,19,85]$ and low degree of specificity for definitive hosts. These results support the existence of a sylvatic life cycle for $T$. callipaeda and indicate that the infestation is mainly maintained by a large number of wildlife species that, altogether, could play a role in spreading the disease in many previously non endemic areas of Europe [11,13-16,86]. Finally, the high prevalence of eyeworms in dogs and wildlife should represent an alert for human populations considering the difficulties in the differential diagnosis of the infection.

\section{Impact of VBH on humans}

Among the zoonotic filarioids, D. immitis and D. repens probably represent the species more frequently reported in humans where they are detected predominantly in the subcutaneous tissues, pulmonary vessels, testicles and also in the central nervous system, causing a range of clinical manifestations from asymptomatic to, more rarely, fatal syndromes $[1,2,66]$. In addition, human infestations by Dirofilaria spp. often induce nodular lesions, which may be erroneously diagnosed as cancers, hence representing a further challenge to physicians [2]. While $D$. immitis is the main agent of human dirofilariosis in the Americas [28,66], D. repens has been accounted for a long time as the sole species that infest humans in Europe $[87,88]$. For example, 28 cases of human dirofilariosis from the Old World erroneously attributed to $D$. immitis were reviewed and re-attributed to D. repens [88]. However, cases of human dirofilariosis by D. immitis have been recently described in Italy, Greece and Spain [89-91] and this trend is at an increase in Europe, most likely paralleling the spread of infestation in dogs in central and north-eastern countries (e.g., south of Switzerland, Czech Republic, Hungary, Serbia and Slovak Republic) [5,7,48-52]. Hundreds of cases of human infestation by VBH have been reported worldwide [1], new cases continue to be reported from new geographic areas and it is likely that many more cases occur and are either unrecognized or go unreported. This is the case of O. lupi, which has probably been misdiagnosed for a long time 
with other filarioids localizing in the eyes. Indeed, O. lupi has only been suspected to act as a causative agent of infestation in humans until recently [92], when this species has been unambiguously identified morphologically and molecularly in two patients from Turkey and one from Tunisia who exhibited clinical features similar to those of the infestation in dogs [92,93]. Human thelaziosis is a condition described in several areas of the former Soviet Union and Asian continent (e.g., China, Korea, Japan, Indonesia, Thailand, Taiwan and India), predominantly in poor, rural communities with low health and socio-economic standards, particularly where domestic dogs and other animals (e.g., cats and foxes) are heavily affected and live in close contact with humans [94]. The first four cases of human thelaziosis in Europe were diagnosed in patients coming from the north-west of Italy, south-eastern France [20] and Spain [21], where the infestation had been previously reported in dogs, cats and foxes $[11,14,16]$. The clinical presentation is characterized by mild conjunctivitis, follicular hypertrophy of the conjunctiva, foreign body sensation, epiphora, itchiness, congestion, swelling, hypersensitivity to light, and keratitis.

Considering the lack of awareness for physicians concerning such exotic parasites (e.g., O. lupi) and the possibility of misidentifications, the impact of VHD on human populations in Europe, mainly in remote rural areas, is much likely underestimated at present.

\section{Managing VBH in dogs and humans Prevention}

From the picture above it emerges how difficult the prevention and the treatment of VBH in endemic areas may be. This is mostly an issue for dirofilarioses in dogs which, in turn, can be easily prevented with a number of macrocyclic lactones administered in a way to kill $D$. immitis or $D$. repens larvae before they develop into adults in the heart/lungs or the subcutis, respectively. Several molecules are available in chewable tablets, spot on and injectable formulations administered with different protocols (Table 1).
Ivermectin is licensed in the Europe to prevent infestations by $D$. immitis and $D$. repens, while spot-on formulations containing moxidectin and selamectin, the oral products containing milbemycin oxime may be further suitable choices for the prevention of $D$. immitis. The injectable long lasting formulation containing moxidectin showed to be effective in controlling $D$. immitis and D. repens infestations for a period of 6 months after a single administration $[95,96]$. The duration of monthly chemoprophylaxis against $D$. immitis (i.e., year round, six months, or only during the vector season) has been debated for long time [97-99]. Current guidelines on management of $D$. immitis infestation in dogs promoted by the European Scientific Counsel on Companion Animal Parasites (ESCCAP) and by the American Heartworm Society (AHS) suggest extending treatment to $7-8$ months or even the year round. The rationale for that relies on the occurrence of certain mosquito vectors, such as St. albopicta, which may survive in temperate areas as adults even during winter and, at least, for nine months per year [100].

In addition, the use of broad-spectrum drug formulations enhance owner compliance and assist continued control of other helminths [99] and of certain ectoparasites according to the associated molecules (Table 1). Interestingly, the massive use of preventive measures against D. immitis infestation showed a decrease in the prevalence of infestation of unprotected dogs living in the same area, through the reduction of reservoir host population. This is the case of some areas of northern Italy where $D$. immitis was regarded as hyper-endemic until 20 years ago, whereas its prevalence decreased over the last decades [47]. Based on this evidence, preventative chemoprophylaxis should be effectively employed also in communities where heartworm prevalence is low or where it is considered emerging [101]. No data is available on the efficacy of macrocyclic lactones against minor species of filarioids (e.g., A. reconditum, A. dracunculoides and Cercopithifilaria spp.) infesting dogs. Consequently, their prevention currently mostly relies on the vector control [37]. Preventing the contact with the fly intermediate host of $T$. callipaeda by the use of bed nets has been recommended for

Table 1 Macrocyclic lactones and dosages licensed in different formulations for the prevention of infestations caused by Dirofilaria immitis (Di) or Dirofilaria repens (Dr) in dogs

\begin{tabular}{llll}
\hline Macrociclic lactone & Formulation & Dosage & Claim \\
\hline Ivermectin & Tablets/Chewables & $6 \mathrm{mcg} / \mathrm{kg}$ & $\mathrm{Di}, \mathrm{Dr}$ \\
Ivermectin/Praziquantel & Chewables & $6 \mathrm{mcg} / \mathrm{kg} / 5 \mathrm{mg} / \mathrm{kg}$ & $\mathrm{Di}, \mathrm{Dr}$ \\
Milbemycin oxime* & Tablets & $0.5 \mathrm{mg} / \mathrm{kg}$ & $\mathrm{Di}$ \\
Moxidectin & Tablets & $3 \mathrm{mcg} / \mathrm{kg}$ & $\mathrm{Di}$ \\
& Injectable & $0.17 \mathrm{mcg} / \mathrm{kg}$ & $\mathrm{Di}, \mathrm{Dr}$ \\
Moxidectin/Imidacloprid & Spot on & $2.5 \mathrm{mg} / \mathrm{Kg} / 10 \mathrm{mg} / \mathrm{kg}$ & $\mathrm{Di}$ \\
Selamectin & Spot on & $6 \mathrm{mg} / \mathrm{kg}$ & $\mathrm{Di}$
\end{tabular}

*Tablets containing either praziquantel or lufenuron are also available for chemoprevention at the same dosage (modified from [66]). 
avoiding human infestation [94]. No information is available on the usefulness of any drug as repellents on animals against $P$. variegata.

\section{Treatments}

The arsenical melarsomine dihydrochloride is the adulticide compound used for the treatment of canine heartworm, associated to confinement of dogs in cages during and for about a month after the treatment period, in order to prevent potentially fatal pulmonary thromboembolism after the death of the heartworms. Melarsomine is usually injected intramuscularly at the dose of $2.5 \mathrm{mg} / \mathrm{kg}$ either in a two-step (first intramuscular injection followed by the second $24 \mathrm{hr}$ later) or threestep (first injection followed by the two-dose protocol 4-6 weeks later) regimen. Even though the three-dose scheme is indicated for those animals with a relevant risk of pulmonary thromboembolism post-treatment, this protocol is recommend by the AHS guidelines for the therapy of all infected dogs [101]. Ivermectin may kill adults of $D$. immitis if administered monthly at the preventive dosage of $6-12 \mu \mathrm{g} / \mathrm{kg}$ for not less than 16-30 months [102]. However, the AHS discourages the extra label use of macrocyclic lactones as primary adulticides albeit their partial efficacy against microfilariae [101]. In fact, such prolonged treatment period does not prevent from the onset of cardiopulmonary damage in the infected dogs, thus impairing a full clinical recovery $[103,104]$. The administration of a macrocyclic lactone for up to 6 months before injecting melarsomine can be beneficial in dogs not requiring urgent therapy, because it can reduce parasite burden and permits immature filarioids to reach adulthood at which time they are fully susceptible to adulticide [66,105]. A novel approach for the treatment of cardiopulmonary dirofilariosis is targeting the Wolbachia rickettsial endosymbionts. Treatment with tetracyclines has been reported to damage $D$. immitis, even causing death of adult worms [106]. Long-lasting administration of both doxycycline and ivermectin before or in the place of melarsomine injections can eliminate adult worms and also reduce risk of thromboembolism. Therefore, it has been suggested that a combination of doxycycline $(10 \mathrm{mg} / \mathrm{kg}$ die for 30 days $)$ and ivermectin ( $6 \mathrm{mcg} / \mathrm{kg}$ every 15 days for 6 months) has a potential efficacy, as high as $73 \%$, in the adulticide therapy in dogs infested with $D$. immitis $[107,108]$.

Although other filarioids of dogs, but not D. immitis, are considered less clinically relevant, microfilaricide treatment is required to control $D$. repens microfilariaassociated syndromes (e.g., cutaneous erythema and ulcerative pruritic lesions) and to decrease the risk of human and animal infestation in endemic areas. However, only little information is available for the treatment of subcutaneous filariosis by $D$. repens, such as a combination of injectable melarsomine and oral administration of macrocyclic lactones [109]. The use of prolonged selamectin or moxidectin administration in treating dogs infected by $D$. repens is reputed effective $[110,111]$. The latter molecule also showed a high degree of efficacy in treating $D$. repens infection, including potential ability to kill adults, after a single administration [112-114]. Surgical options usually rely on heartworm removal by the use of flexible alligator forceps with the aid of fluoroscopy- or trans-oesophageal echocardiography- guides, but the success of these procedures may be influenced by several factors [115].

Although minor species of filarioids infesting dogs, (e.g., A. reconditum, A. dracunculoides and Cercopithifilaria spp.), are considered clinically irrelevant, microfilaricide treatment should be always advocated to limit the reservoir function of infected hosts. Though reports on microfilaricide treatment for minor species are scant, evidence suggests that macrocyclic lactones (e.g., ivermectin, selamectin and moxidectin) are effective against patent infestation when administered at the same dosage recommended for $D$. immitis [116,117].

As far as O. lupi infestation, surgical removal of the nodules containing the worms remains the only curative treatment for ocular onchocercosis, even thought developmental stages present in periocular tissues and other parts of the body may cause relapses [32]. No specific pharmacological treatments have been reported yet for $O$. lupi infestation in dogs.

Treatment of domestic animals infested by T. callipaeda should be carried out and the topic instillation of organophosphates [118] or moxidectin 1\% [119] showed to be highly effective. Imidacloprid $10 \%$ and moxidectin $2.5 \%$ in spot-on formulation was also effective for the control of dog thelaziosis within five (90.47\%) to nine (95.23\%) days after treatment [120], allowing to overcome problems due to the mechanical removal of parasites or to the restraining of the animals for the local instillation of drugs in the eyes. The administration of an injectable sustained-release formulation of moxidectin and of a monthly treatment with milbemycin oxime provided some seasonal protection against $T$. callipaeda infestation in dogs from an endemic area of northern Italy $[121,122]$. Such a chemoprophylaxis approach would more likely reduce the prevalence of dog thelaziosis, and therefore the risk for human infestations in endemic areas.

\section{Diagnosis}

Laboratory diagnosis of infestations caused by $D$. immitis, $D$. repens or A. reconditum is achieved through classical detection of circulating microfilariae, parasite antigens and/or by genetic tools. Microfilariae can be identified in the bloodstream of infected animals by microscopic techniques, using the Knott's test, which is the gold 
standard method [66]. Blood circulating microfilariae of $D$. immitis should be discriminated from those of other filarioids that do not infest the heart chambers and arteries (i.e. $D$. repens and $A$. reconditum). Key diagnostic features are differences in morphology and size measurements of particular structures. Head of $D$. immitis is slightly tapered, while that of $A$. reconditum and $D$. repens is blunt. The use of fixation in $2 \%$ formalin in the Knott's test can cause a distinctive artefact in the tail of A. reconditum and $D$. repens which become curved ("buttonhook" or "umbrella" tail), while that of D. immitis remains straight [123,124]. Given that the occurrence of such an artefact may vary considerably, the possibility that $A$. reconditum and $D$. repens larvae present a straight tail cannot be ruled out. Hence, the body length becomes discriminatory for the identification at the species level. Indeed, microfilariae of $D$. immitis are $260-340 \mathrm{~mm}$ in length and 5-7.5 $\mathrm{mm}$ in width, while those of $D$. repens are longer and slightly wider $(325-380 \times 5-8 \mathrm{~mm})$ and those of $A$. reconditum are smaller and thinner $(240-290 \times 4.5-5.5 \mathrm{~mm})[123,124]$. However, microscopic detection of circulating microfilariae may lack in sensitivity. Single-sex infestations, low parasite burdens, immune reactions or past administration of parasiticides with microfilaricidal activity may cause lack of circulating larvae in up to $20-30 \%$ of dogs infected by D. immitis [66]. An alternative method for diagnosing D. immitis infestation in dogs is the use of commercial kits for the detection of antigens released in the blood by adult females. However, some microfilaraemic animals may score negative at these tests for the low worm burden or for the persistence of microfilariae after the death of adult worms $[66,112,113]$. No similar tests are available for the other filarioids. Other diagnostic tools may include echocardiography, which has high sensitivity although requiring high professional expertise while performing the test [125].

Dermal microfilariae of O. lupi and Cercopithifilaria spp. can be detected by skin biopsies. Interestingly, it has been demonstrated that microfilariae of the latter species are unevenly distributed on the body of an infected dog with, however, higher frequencies on the interscapular region and on the head, where the tick vectors usually attach [38]. It should also be taken into account that at least three Cercopithifilaria spp., two still unidentified at the species level, may infest dogs. However, dermal microfilariae of these three species can be differentiated morphologically based on their length and presence/absence of lateral alae [36].

Recent molecular-based assays have been reported for the unequivocal identification of filarioids, irrespective of their life cycle stage. Ribosomal or mitochondrial DNA sequence fragments of $D$. immitis, D. repens and A. reconditum may be amplified and analysed with a restriction fragment length polymorphism, specific PCR amplifications or with primers yielding species-specific amplicons [126,127] and their usefulness has been demonstrated in epidemiological and clinical studies $[112,128,129]$. Recently, a duplex real-time PCR has been assessed for the discrimination between $D$. immitis and $D$. repens and their quantification in blood samples and mosquitoes [130]. A multiplex PCR based on the amplification of a mitochondrial gene of bloodcirculating microfilariae of $D$. immitis, A. reconditum and D. repens and of Cercopithifilaria spp. has also been shown to be useful for their molecular detection and differentiation in blood and skin samples [131]. Finally, a multicentre study in the Mediterranean area proved that the three species of Cercopithifilaria affecting dogs might be discriminated from each other by differences in mitochondrial cox 1 and ribosomal $12 \mathrm{~S}$ sequences [36].

\section{Conclusions}

Although great scientific achievements have been gained over the past decades on several aspects of the biology, epidemiology, control and treatment for many VBH (e.g., $D$. immitis and $D$. repens), most of them have only been recently known to science, thus they remain enigmatic in many ways. The increasing trend of VBH in Europe is most likely due to the spreading process of several arthropod vector species and highlights the need for actions focussing on control of the vectors in the environment and the protection of animals at individual and population levels. Indeed public health authorities should be concerned about the potential risk of introduction and establishment of new and exotic vectors, which may alter the VBH scenario in a manner that may not be easily foreseeable.

The biological mechanisms behind the increased number of cases of VBH in Europe remain uncertain and research on the role played by insect vectors for many of them is lacking. This is only partially due to the complexity of the relationship between pathogen, host and vector. Indeed, some VBH are relatively poorly investigated and this lack of awareness represents a major constraint to their successful management and control in endemic and non-endemic areas. For example, veterinary/medical surveillance accompanied by entomological surveillance is essential to prevent the spread of filaroids and to evaluate the risk of zoonotic filariosis outbreaks. There is a need to monitor closely the changing epidemiology of VBH in order to predict their future distribution, particularly in light of their constant spread and of socio-economic and political events. Under the above circumstances, the economic crisis and the subsequent population movements from southern to central and northern European areas may render it difficult to afford 
effective therapeutic treatments and a correct management of the environment, towards the reduction of arthropod vector breeding sites.

In addition, although basic and applied research in the biology of insect vectors is often considered the 'Cinderella' in the political agenda of governmental funding agencies, these are essential for controlling arthropods and VBH, especially given the introduction of European directives which limit the number of available biocides (e.g. 98/8/EC) and ban the aerial use of insecticides (e.g., P6-TA- (2009) 0010) within the European Union. Since the range of alternatives is limited, identifying novel control strategies is essential.

\section{Competing interests}

The authors declare that there are no competing interests.

\section{Authors' contributions}

DO conceived the review and wrote the first draft of the manuscript with $\mathrm{GC}, \mathrm{DP}, \mathrm{FD}-\mathrm{T}, \mathrm{EB}, \mathrm{CG}, \mathrm{DT}$. All authors equally contributed with the revision of the manuscript. EB elaborated figures. All authors read and approved the final version of the manuscript.

\section{Acknowledgments}

The authors are grateful to Rafael Antonio do Nascimento Ramos (University of Bari, Italy) and Aleksandra Ignjatović Ćupina (University of Novi Sad, Serbia) for their support during the preparation of the manuscript.

This article is dedicated to the memory of our friend and colleague Odile Bain (Born in Paris the 28th April 1939; died in Paris the 16th October 2012) whose scientific studies contributed to greatly enhance our understanding of filarioids. We will never forget her contagious passion and unbound curiosity for parasitology. Odile's tenacity and attitude towards sharing her invaluable knowledge with peers will remain amongst her most important legacy.

\section{Author details}

'Dipartimento di Medicina Veterinaria, Università degli Studi di Bari, Bari, Valenzano, Italy. ${ }^{2}$ Departamento de Imunologia, Centro de Pesquisas Aggeu Magalhães (Fiocruz-PE), Recife, Pernambuco, Brazil. ${ }^{3}$ Dipartimento di Sanità Pubblica Veterinaria, Università degli Studi di Messina, Messina, Italy. ${ }^{4}$ Dipartimento di Scienze Biomediche Comparate, Università degli Studi di Teramo, Teramo, Italy. ${ }^{5}$ Laboratory for Medical and Veterinary Entomology, Faculty of Agriculture, University of Novi Sad, Novi Sad, Serbia. ${ }^{6}$ Dipartimento di Patologia Animale, Igiene e Sanità Pubblica Veterinaria, Università degli Studi di Milan, Milan, Italy. ${ }^{7}$ Istituto Zooprofilattico Sperimentale delle Venezie, Legnaro, Padova, Italy.

Received: 22 October 2012 Accepted: 1 January 2013

Published: 16 January 2013

\section{References}

1. Otranto $D$, Eberhard ML: Zoonotic helminths affecting the human eye. Parasit Vectors 2011, 23:41.

2. Genchi C, Kramer LH, Rivasi F: Dirofilarial infections in Europe. Vector Borne Zoonotic Dis 2011, 11:1307-1317.

3. Morchón R, Carretón E, González-Miguel J, Mellado-Hernández I: Heartworm disease (Dirofilaria immitis) and their vectors in Europe - new distribution trends. Front Physiol 2012, 3:196.

4. Petrić D, Zgomba M, Bellini R, Becker N: Surveillance of Mosquito Populations: A Key Element to Understanding the Spread of Invasive Vector Species and Vector-Borne Diseases in Europe. In Essays on Fundamental and Applied Environmental Topics. Edited by Mihailović D. Hauppauge, New York: Nova Science Publishers; 2012:192-224.

5. Colwell DD, Dantas-Torres F, Otranto D: Vector-borne parasitic zoonoses: emerging scenarios and new perspectives. Vet Parasitol 2010, 24:14-21.

6. Otranto D, Brianti E, Latrofa MS, Annoscia G, Weigl S, Lia RP, Gaglio G, Napoli E, Giannetto S, Papadopoulos E, Mirò G, Dantas-Torres F, Bain O: On a Cercopithifilaria sp. transmitted by Rhipicephalus sanguineus: a neglected, but widespread filarioid of dogs. Parasit Vectors 2012, 5:1.

7. Genchi C, Rinaldi L, Mortarino M, Genchi M, Cringoli G: Climate and Dirofilaria infection in Europe. Vet Parasitol 2009, 163:286-292.

8. Becker N, Petrić D, Zgomba M, Boase C, Madon M, Dahl C, Kaiser A: Mosquitoes and their control. Berlin Heidelberg: Springer - Verlag; 2010.

9. Brianti E, Gaglio G, Napoli E, Giannetto S, Dantas-Torres F, Bain O, Otranto D: New insights into the ecology and biology of Acanthocheilonema reconditum (Grassi, 1889) causing canine subcutaneous filariosis. Parasitology 2012, 139(4):530-536.

10. Otranto D, Dantas-Torres F, Mallia E, DiGeronimo PM, Brianti E, Testini G, Traversa D, Lia RP: Thelazia callipaeda (Spirurida, Thelaziidae) in wild animals: report of new host species and ecological implications. Vet Parasitol 2009, 166:262-267.

11. Dorchies P, Chaudieu G, Simeon LA, Cazalot G, Cantacessi C, Otranto D: First reports of autochthonous eyeworm infection by Thelazia callipaeda (Spirurida, Thelaziidae) in dogs and cat from France. Vet Parasitol 2007, 149:294-297.

12. Ruytoor P, Dean E, Pennant O, Dorchies P, Chermette R, Otranto D, Guillot J: Ocular thelaziosis in dogs. France. Emerg Infect Dis 2010, 16:1943-1945.

13. Malacrida F, Hegglin D, Bacciarini L, Otranto D, Nägeli F, Nägeli $C$, Bernasconi C, Scheu U, Balli A, Marenco M, Togni L, Deplazes P, Schnyder M: Emergence of canine ocular thelaziosis caused by Thelazia callipaeda in southern Switzerland. Vet Parasitol 2008, 157:321-327.

14. Miró G, Montoya A, Hernández L, Dado D, Vázquez MV, Benito M, Villagrasa M, Brianti E, Otranto D: Thelazia callipaeda infection in dogs: a new parasite for Spain. Parasit Vectors 2011, 27:148.

15. Vieira L, Rodrigues FT, Costa A, Diz-Lopes D, Machado J, Coutinho T, Tuna J, Latrofa MS, Cardoso L, Otranto D: First report of canine ocular thelaziosis by Thelazia callipaeda in Portugal. Parasit Vectors 2012, 21:124.

16. Otranto D, Ferroglio E, Lia RP, Traversa D, Rossi L: Current status and epidemiological observation of Thelazia callipaeda (Spirurida, Thelaziidae) in dogs, cats and foxes in Italy: a "coincidence" or a parasitic disease of the Old Continent? Vet Parasitol 2003, 116:315-325.

17. Anderson RC: Nematode parasites of vertebrates. Their development and transmission. Wallingford, UK: CABI Publishing; 2000.

18. Otranto D, Lia RP, Cantacessi C, Testini G, Troccoli A, Shen JL, Wang ZX: Nematode biology and larval development of Thelazia callipaeda (Spirurida, Thelaziidae) in the drosophilid intermediate host in Europe and China. Parasitology 2005, 131:847-855.

19. Otranto D, Cantacessi C, Testini G, Lia RP: Phortica variegata as an intermediate host of Thelazia callipaeda under natural conditions: evidence for pathogen transmission by a male arthropod vector. Int J Parasitol 2006, 36:1167-1173.

20. Otranto D, Dutto M: Human thelaziosis Europe. Emerg Infect Dis 2008, 14:647-649.

21. Fuentes I, Montes I, Saugar JM, Latrofa S, Gárate T, Otranto D: Thelaziosis, a Zoonotic Infection, Spain, 2011. Emerg Infect Dis, in press.

22. Egyed Z, Sréter T, Széll Z, Beszteri B, Oravecz, Márialigeti K, Varga I: Morphologic and genetic characterization of Onchocerca lupi infesting dogs. Vet Parasitol 2001, 102:309-319.

23. Széll Z, Erdélyi I, Sréter T, Albert M, Varga I: Canine ocular onchocercosis in Hungary. Vet Parasitol 2001, 97:245-251.

24. Komnenou A, Eberhard ML, Kaldrymidou E, Tsalie E, Dessiris A: Subconjunctival filariasis due to Onchocerca sp. in dogs: report of 23 cases in Greece. Vet Ophthalmol 2002, 5:119-126.

25. Hermosilla A, Hetzel U, Bausch M, Grübl J, Bauer C: First autochthonous case of canine ocular onchocercosis in Germany. Vet Rec 2005, 154:450-452.

26. Sréter-Lancz Z, Széll Z, Sréter T: Molecular genetic comparison of Onchocerca sp. infecting dogs in Europe with other spirurid nematodes including Onchocerca lienalis. Vet Parasitol 2007, 148:365-370.

27. Faísca P, Morales-Hojas R, Alves M, Gomes J, Botelho M, Melo M, Xufre A: A case of canine ocular onchocercosis in Portugal. Vet Ophthalmol 2010, 13:117-121.

28. Orihel TC, Ash LR, Holshuh HJ, Santenelli S: Onchocerciasis in a California dog. Am J Trop Med Hyg 1991, 44:513-517.

29. Eberhard ML, Ortega Y, Dial S, Schiller CA, Sears AW, Greiner E: Ocular Onchocerca infections in western United States. Vet Parasitol 2000, 90:333-338.

30. Zarfoss MK, Dubielzig RR, Eberhard ML, Schmidt KS: Canine ocular onchocerciasis in the United States: two new cases and a review of the literature. Vet Ophthalmol 2005, 8:51-57.

31. Labelle AL, Daniels JB, Dix M, Labelle P: Onchocerca lupi causing ocular disease in two cats. Vet Ophthalmol 2011, Suppl 1:105-110. 
32. Sréter T, Széll Z: Onchocercosis: a newly recognized disease in dogs. Vet Parasitol 2008, 151:1-13.

33. Otranto D, Dantas-Torres F, Papadopoulos E, Petrić D, Ćupina Al, Bain O: Tracking the vector of Onchocerca lupi in a rural area of Greece. Emerg Infect Dis 2012, 18:1196-1200.

34. Bain O, Uni S, Takaoka H: A synthetic look at a twenty years old taxon, Cercopithifilaria its probable evolution. In Proceedings of the 10th International Congress of Parasitology (ICOPA): Vancouver. 2002.

35. Otranto D, Brianti E, Dantas-Torres F, Weigl S, Latrofa MS, Gaglio G, Cauquil L, Giannetto S, Bain O: Morphological and molecular data on a Cercopithifilaria species from the dog skin. Vet Parasitol 2011, 182:221-229.

36. Otranto D, Brianti E, Dantas-Torres F, Miró G, Latrofa MS, Mutafchiev Y, Bain O: Species diversity of dermal microfilariae of the genus Cercopithifilaria infesting dogs in the Mediterranean region. Parasitology 2012, 23:1-10.

37. Brianti E, Otranto D, Dantas-Torres F, Weigl S, Latrofa MS, Gaglio G, Napoli E, Brucato G, Cauquil L, Giannetto S, Bain O: Rhipicephalus sanguineus (Ixodida, Ixodidae) as intermediate host of a canine neglected filarial species with dermal microfilariae. Vet Parasitol 2011, 183:330-337.

38. Otranto D, Brianti E, Abramo F, Gaglio G, Napoli E, Latrofa MS, Ramos RA Dantas-Torres F, Bain O: Cutaneous distribution and localization of Cercopithifilaria sp. microfilariae in dogs. Vet Parasitol 2012, 190:143-150.

39. Root TL, Price JT, Hall KR, Schneider SH, Rosenzweig C, Pounds JA: Fingerprints of global warming on wild animals and plants. Nature 2003, 421:57-60.

40. Khasnis AA, Nettleman MD: Global warming and infectious disease. Arch Med Res 2005, 36:689-696.

41. Purse BV, Mellor PS, Rogers DJ, Samuel AR, Mertens PP, Baylis M: Climate change and the recent emergence of bluetongue in Europe. Nat Rev Microbiol 2005, 3:171-181.

42. Semenza JC, Menne B: Climate change and infectious diseases in Europe. Lancet Infect Dis 2009, 9:365-375.

43. European Centre for Disease Prevention and Control (ECDC): First meeting of ECDC Expert Group on Climate Change. Stockholm; 2009 [http://www.ecdc. europa.eu/en/publications/Publications/0910_MER_First_Meeting_of_ ECDC_Expert_Group_on_Climate_Change.pdf].

44. Wilson N, Lush D, Baker MG: Meteorological and climate change themes at the 2010 International Conference on Emerging Infectious Diseases. Euro Surveill 2010, 15:pii=19627.

45. Sabatini A, Raineri V, Trovato G, Coluzzi M: Aedes albopictus in Italia e possibile diffusione della specie nell'area del mediterraneo. Parassitologia 1990, 32:301-304.

46. Cancrini G, Ricci I, Tessarin C, Gabrielli S, Pietrobelli M: Aedes albopictus is a natural vector of Dirofilaria immitis in Italy. Vet Parasitol 2003, 118:195-202.

47. Otranto D, Capelli G, Genchi C: Changing distribution patterns of canince vector borne disease in Italy: leishmaniosis vs. dirofilariosis. Parasit Vectors 2009, 26:Suppl 1 S2.

48. Genchi C, Rinaldi L, Cascone C, Mortasino M, Cringoli G: Is heartworm disease really spreading in Europe? Vet Parasitol 2005, 133:137-148.

49. Svobodova V, Misonova P: The potential risk of Dirofilaria immitis becoming established in the Czech Republic by imported dogs. Vet Parasitol 2005, 128:137-140.

50. Svobodova Z, Svobodova V, Genchi C, Forejtek P: The first report of autochthonous dirofilariosis in dogs in the Czech Republic. Helminthol 2006, 43:242-245.

51. Babal P, Kobzova D, Novak I, Dubinsky P, Jalili N: First case of cutaneous human dirofilariosis in Slovak Republic. Bratis/ Lek List 2008, 109:486-488.

52. Tasić A, Rossi L, Tasić S, Miladinović-Tasić N, llić T, Dimitrijević S: Survey of canine dirofilariasis in Vojvodina. Serbia. Parasitol Res 2008, 103:1297-1302.

53. Otranto D, Dantas-Torres F: Canine and feline vector-borne diseases in Italy: current situation and perspectives. Parasit Vectors 2010, 3:2.

54. Ignjatovic Cupina A, Petric D, Papadopoulos E, Ptochos S, Otranto D, Dantas-Torres F, Mutafchiev J, Bain O: Notes on blackfly fauna in Western Thrace (northeastern Greece). The British Simuliid Group Bulletin, in press.

55. Crosskey RW: The Natural History of Blackflies. British Museum (Natural History):: John Wiley \& Sons Ltd; 1990.

56. O'Dwyer LA, Burton DL: Potential meets reality: GIS and public health research in Australia. Aust N Z J Publ Heal 1998, 22:819-223.

57. Liebhold AM, Rossi RE, Kemp WP: Geostatistics and geographic information systems in applied insect ecology. Annu Rev Entomol 1993, 38:303-327.

58. Kitron U: Landscape ecology and epidemiology of vector-borne diseases: tools for spatial analysis. J Med Entomol 1998, 35:435-445.
59. Caminade C, Medlock JM, Ducheyne E, McIntyre KM, Leach S, Baylis M, Morse AP: Suitability of European climate for the Aedes albopictus: recent trends and future scenarios. J R Soc Interface 2012, 9:2708-2717.

60. Santa-Ana M, Khadem M, Capela R: Natural infection of Culex theileri (Diptera, Culicidae) with Dirofilaria immitis (Nematoda, Filarioidea) on Madeira Island, Portugal. J Med Entomol 2006, 43:104-106.

61. Cancrini G, Magi M, Gabrielli S, Arispici M, Tolari F, Dell'Omodarme M, Prati MC: Natural vectors of dirofilariasis in rural and urban areas of the Tuscan region, central Italy. J Med Entomol 2006, 43:574-579.

62. Petruschke G, Rossi L, Genchi C, Pollono F: Canine dirofilariasis in the canton of Ticino and in the neighboring areas of northern Italy. Schweiz Arch Tierheilkd 2001, 143:141-147.

63. Yildirim A, Inci A, Duzlu O, Biskin Z, Ica A, Sahin I: Aedes vexans and Culex pipiens as the potential vectors of Dirofilaria immitis in Central Turkey. Vet Parasitol 2011, 178:143-147.

64. Latrofa MS, Montarsi F, Ciocchetta S, Annoscia G, Dantas-Torres F, Ravagnan S, Capelli G, Otranto D: Molecular xenomonitoring of Dirofilaria immitis and Dirofilaria repens in mosquitoes from north-eastern Italy by real-time PCR coupled with melting curve analysis. Parasit Vectors 2012, 5:76.

65. Roggero C, Schaffner F, Bächli G, Mathis A, Schnyder M: Survey of Phortica drosophilid flies within and outside of a recently identified transmission area of the eye worm Thelazia callipaeda in Switzerland. Vet Parasitol 2010, 171:58-67.

66. McCall JW, Genchi C, Kramer LH, Guerrero J, Venco L: Heartworm disease in animals and humans. Adv Parasitol 2008, 66:193-285.

67. Pietrobelli M, Cancrini G, Capelli G, Frangipane di Regalbono A: Potential vectors for canine and humans dirofilariosis in North East Italy. Parassitologia 2000, 42(Suppl. 1):104.

68. Genchi C, Di Sacco B, Cancrini G: Epizootiology of canine and feline heartworm infection in northern Italy: possible mosquito vectors. In Proceedings of heartworm Symposium: 1992.

69. Labarthe N, Serrão ML, Melo YF, de Oliveira SJ, Lourenço-de-Oliveira R: Mosquito frequency and feeding habits in an enzootic canine dirofilariasis area in Niterói, state of Rio de Janeiro, Brazil. Mem Inst Oswaldo Cruz 1998, 93:145-154.

70. Venco L, Genchi C, Genchi M, Grandi G, Kramer LH: Clinical evolution and radiographic findings of feline heartworm infection in asymptomatic cats. Vet Parasitol 2008, 158:232-237.

71. Ledesma N, Harrington L: Mosquito vectors of dog heartworm in the United States: vector status and factors influencing transmission efficiency. Top Companion Anim Med 2011, 26:178-185.

72. ECDC: European Network for Arthropod Vector Surveillance for Human Public Health; [http://ecdc.europa.eu/en/activities/diseaseprogrammes/ emerging_and_vector_borne_diseases/Pages/vBORNET_maps.aspx].

73. Cancrini G, Scaramozzino P, Gabrielli S, Di Paolo M, Toma L, Romi R: Aedes albopictus and Culex pipiens implicated as natural vectors of Dirofilaria repens in central Italy. J Med Entomol 2007, 44:1064-1066.

74. Cancrini G, Romi R, Gabrielli S, Toma L, Di Paolo M, Scaramozzino P: First finding of Dirofilaria repens in a natural population of Aedes albopictus. Med Vet Entomol 2003, 17:448-451.

75. Versteirt V, De Clercq E, Dekoninck W, Damiens D, Ayrinhac A, Jacobs F, Van Bortel W: Mosquito vectors of disease: spatial biodiversity, drivers of change, and risk". Final Report. Brussels: Belgian Science Policy; 2009:152. (Research Programme Science for a Sustainable Development); available online at http://www.belspo.be/belspo/SSD/science/Reports/FinalReport_ MODIRISK\%20ML.pdf.

76. Capelli G, Drago A, Martini S, Montarsi F, Soppelsa M, Delai N, Ravagnan S, Mazzon L, Schaffner F, Mathis A, Di Luca M, Romi R, Russo F: First report in Italy of the exotic mosquito species Aedes (Finlaya) koreicus, a potential vector of arboviruses and filariae. Parasit Vectors 2011, 28:188.

77. ECDC: European Network for Arthropod Vector Surveillance for Human Public Health; [http://ecdc.europa.eu/en/activities/diseaseprogrammes/ emerging_and_vector_borne_diseases/Pages/VBORNET_maps.aspx].

78. Di Cesare A, Castagna G, Meloni S, Milillo P, Latrofa S, Otranto D, Traversa D: Canine and feline infections by cardiopulmonary nematodes in central and southern Italy. Parasitol Res 2011, 109:S87-S96.

79. Gortazar C, Castillo JA, Lucientes J, Blanco JC, Arriolabengoa A, Calvete C Factors affecting Dirofilaria immitis prevalence in red foxes in northeastern Spain. J Wildl Dis 1994, 30:545-547. 
80. Magi M, Calderini P, Gabrielli S, Dell'Omodarme M, Macchioni F, Prati MC, Cancrini G: Vulpes vulpes: a possible wild reservoir for zoonotic filariae. Vector Borne Zoonotic Dis 2008, 8:249-252.

81. Shimalov W, Pen'kevich VA: Helminth fauna of the wolf (Canis lupus Linnaeus, 1758) in Belorussian Polesie. Parazitologiia 2012, 46:118-126.

82. Kirkova Z, Ivanov A, Georgieva D: Dirofilariosis in dogs and wild carnivores in Bulgaria. In Dirofilaria immitis and D. repens in Dog and Cat and Human Infections. Edited by Genchi C, Rinaldi L, Cringoli G.: ; 2007.

83. Torres J, Feliu C, Fernández-Morán J, Ruíz-Olmo J, Rosoux R, Santos-Reis M, Miquel J, Fons R: Helminth parasites of the Eurasian otter Lutra lutra in southwest Europe. J Helminthol 2004, 78:353-359.

84. Molnar $V$, Pazár $P$, Rigó $D$, Máthé $D$, Fok E, Glávits $R$, Vajdovich $P$, Jacsó $O$, Balogh L, Sós E: Autochthonous Dirofilaria immitis infection in a ferret with aberrant larval migration in Europe. J Small Anim Pract 2010, 51:393-396.

85. Otranto D, Testini G, Deluca F, Hu M, Shamsi S, Gasser RB: Analysis of genetic variability within Thelazia callipaeda (Nematoda: Thelazioidea) from Europe and Asia by sequencing and mutation scanning of mitochondrial cytochrome c oxidase subunit 1. Mol Cell Probes 2005, 19:306-313.

86. Hermosilla C, Herrmann B, Bauer C: First case of Thelazia callipaeda infection in a dog in Germany. Vet Rec 2004, 154:568-669.

87. Pampiglione S, Canestri Trotti G, Rivasi F: Human dirofilariasis due to Dirofilaria (Nochtiella) repens in Italy: a review of word literature. Parassitologia 1995, 37:149-193.

88. Pampiglione S, Rivasi F, Gustinelli A: Dirofilarial human cases in the old world, attributed to Dirofilaria immitis: a critical analysis. Histopathology 2009, 54:192-204.

89. Miliaras D, Meditskou S, Kelekis A, Papachristos I: Human pulmonary Dirofilariasis: one more case in Greece suggests that Dirofilaria is a rather common cause of coin lesions in the lungs in endemic areas of Europe. Int J Immunopathol Pharmacol 2010, 23:345-348.

90. Morchón R, Moya I, González-Miguel J, Montoya MN, Simón F: Zoonotic Dirofilaria immitis infections in a province of Northern Spain. Epidemiol Infect 2010, 138(3):380-383.

91. Avellis FO, Kramer LH, Mora P, Bartolino A, Benedetti P, Rivasi F: A case of human conjunctival dirofilariosis by Dirofilaria immitis in Italy. Vector Borne Zoonotic Dis 2011, 11:451-452.

92. Otranto D, Sakru N, Testini G, Gürlü VP, Yakar K, Lia RP, Dantas-Torres F, Bain O: Case report: first evidence of human zoonotic infection by Onchocerca lupi (Spirurida, Onchocercidae). Am J Trop Med Hyg 2011, 84:55-58.

93. Otranto D, Dantas-Torres F, Cebeci Z, Yeniad B, Buyukbabani N, Boral OB, Gustinelli A, Mounir T, Mutafchiev Y, Bain O: Human ocular filariasis: further evidence on the zoonotic role of Onchocerca lupi. Parasit Vectors 2012, 27:84.

94. Shen J, Gasser RB, Chu D, Wang Z, Yuan X, Cantacessi C, Otranto D: Human thelaziosis-a neglected parasitic disease of the eye. J Parasitol 2006 92:872-875.

95. Genchi C, Rossi L, Cardini G, Kramer LH, Venco L, Casiraghi M, Genchi M, Agostini A: Full season efficacy of moxidectin microsphere sustained release formulation for prevention of hearworm (Dirofilaria immitis) infection in dogs. Vet Parasitol 2002, 110:85-91.

96. Genchi M, Pengo G, Genchi C: Efficacy of moxidectin microsphere sustained release formulation for the prevention of subcutaneous filarial infections (Dirofilaria repens) in dogs. Vet Parasitol 2010, 170:167-69.

97. Knight DH, Lok JB: Seasonal timing of heartworm chemoprophylaxis in the United States. In Proceedings of the Heartworm Symposium 1995 Washington, D.C., U.S.A: American Hearthworm Society; 1995:36-42.

98. Slocombe JOB, Bhactendu-Srivastava B, Surgeoner GA: The transmission period for heartworm in Canada. In Proceedings of the Heartworm Symposium 1995. Washington, D.C., U.S.A: American Hearthworm Society; 1995:43-48.

99. Bowman DD: Georgi's Parasitology for Veterinarians. 7th edition. Philadelphia: Saunders Elsevier; 2002.

100. Romi R, Severini F, Toma L: Cold acclimation and overwintering of female Aedes albopictus in Roma. J Am Mosa Control Assoc 2006, 22:149-151.

101. Nelson CT, McCall JW, Rubin SB, Buzhardt LF, Doiron DW, Graham W, Longhofer SL, Guerrero J, Robertson-Plough C, Paul A: Guidelines for the diagnosis, prevention and management of heartworm (Dirofilaria immitis) infection in dogs. Vet Parasitol 2005, 133:255-266.

102. McCall JW, Guerrero J, Roberts RE, Supakorndej N, Mansour AE, Dzimianski MT, McCall SD: Further evidence of clinical prophylactic (reach-back) and adulticidal activity of monthly administration of ivermectin and pyrantel pamoate (Heartgard Plus) in dogs experimentally infected with heartworms: In Proceedings of the American Heartworm Symposium, Batavia, IL. Edited by L. Seward, 2001:189-200.

103. Rawlings CA, Bowman DD, Howerth EW, Stansfield DG, Legg W, Luempert LG: Response of dogs treated with ivermectin or milbemycin starting at various intervals after Dirofilaria immitis infection. Vet Ther 2001, 2:193-207.

104. Venco L, McCall JW, Guerrero J, Genchi C: Efficacy of long-term monthly administration of ivermectin on the progress of naturally acquired heartworm infection in dogs. Vet Parasitol 2004, 124:259-268.

105. Atkins C, Miller MW: Is there a better way to administer heartworm adulticidal therapy? Vet Med 2003, 98:310-317.

106. Kramer L, Grandi G, Leoni M, Passeri B, McCall J, Genchi C, Mortarino M, Bazzocchi C: Wolbachia and its influence on the pathology and immunology of Dirofilaria immitis infection. Vet Parasitol 2008, 158:191-195.

107. Bazzocchi C, Mortarino M, Grandi G, Kramer LH, Genchi C, Bandi C, Genchi M, Sacchi L, McCall JW: Combined ivermectin and doxycycline treatment has microfilaricidal and adulticidal activity against Dirofilaria immitis in experimentally infected dogs. Int J Parasitol 2008, 38:1401-1410.

108. Grandi G, Quintavalla C, Mavropoulou A, Genchi M, Gnudi G, Bertoni G, Kramer LH: A combination of doxycycline and ivermectin is adulticidal in dogs with naturally acquired heartworm disease (Dirofilaria immitis). Vet Parasitol 2010, 169:347-351.

109. Baneth G, Volansky Z, Anug Y: Dirofilaria repens infection in a dog: diagnosis and treatment with melarsomine and doramectin. Vet Parasitol 2002, 105:173-178.

110. Fok E, Jacsó O, Szebeni Z, Gyorffy A, Sükösd L, Lukács Z, Schaper R: Elimination of Dirofilaria (syn. Nochtiella) repens microfilariae in dogs with monthly treatments of moxidectin $2.5 \%$ /imidacloprid $10 \%$ (Advocate, Bayer) spot-on. Parasitol Res 2010, 106:1141-1149.

111. Jacsó $O$, Fok $E$, Kiss $G$, Kökény $G$, Lang Z: Preliminary findings on the efficacy of selamectin in the treatment of dogs naturally infected with Dirofilaria repens. Acta Vet Hung 2010, 58:405-412.

112. Traversa D, Aste G, Milillo P, Capelli G, Pampurini F, Tunesi C, Santori D, Paoletti B, Boari A: Autochthonous foci of canine and feline infections by Dirofilaria immitis and Dirofilaria repens in central Italy. Vet Parasitol 2010, 169:128-132.

113. Traversa D, Aste G, Di Cesare A, Paoletti B, Di Tommaso M, Di Giulio E, Pampurini F, Tunesi $C$, Boari A: Efficacy of a single administration of a spot-on solution containing imidacloprid $10 \%$ /moxidectin $2.5 \%$ in eliminating Dirofilaria repens microfilariae in naturally infected dogs. Vet Parasitol 2011, 179:107-112.

114. Hellmann K, Heine J, Braun G, Paran-Dobesova R, Svobodova V: Evaluation of the therapeutic and preventive efficacy of $2.5 \%$ moxidectin / $10 \%$ imidacloprid (Advocate $\left({ }^{\circledR}\right)$, Bayer animal health) in dogs naturally infected or at risk of natural infection by Dirofilaria repens. Parasitol Res 2011, 109:S77-86.

115. Arita N, Yamane I, Takemura N: Comparison of canine heartworm removal rates using flexible alligator forceps guided by transesophageal echocardiography and fluoroscopy. J Vet Med Sci 2003, 65:259-261.

116. Lindemann BA, McCall JW: Microfilaricidal activity of ivermectin against Dipetalonema reconditum. J Vet Pharmacol Ther 1983, 6:75-76.

117. Venco L, Kramer L, Genchi C: Heartworm disease in dogs: unusual clinical cases. Vet Parasitol 2005, 133:207-218.

118. Rossi L, Peruccio C: Thelaziosi oculare nel Cane: aspetti clinici e terapeutici. Veterinaria 1989, B:47-50.

119. Lia RP, Traversa D, Agostini A, Otranto D: Field efficacy of moxidectin 1 per cent against Thelazia callipaeda in naturally infected dogs. Vet Rec 2004, 154:143-145.

120. Bianciardi P, Otranto D: Treatment of dog thelaziosis caused by Thelazia callipaeda (Spirurida, Thelaziidae) using a topical formulation of imidacloprid $10 \%$ and moxidectin 2.5\%. Vet Parasitol 2005, 129:89-93.

121. Rossi L, Rigano C, Tomio E, Frassetto D, Ferroglio E: Use of sustainedrelease moxidectin to prevent eyeworm (Thelazia callipaeda) infection in dogs. Vet Rec 2007, 161:820-821.

122. Ferroglio E, Rossi L, Tomio E, Schenker R, Bianciardi P: Therapeutic and prophylactic efficacy of milbemycin oxime (Interceptor) against Thelazia callipaeda in naturally exposed dogs. Vet Parasitol 2008, 154:351-353.

123. Sloss MW, Kemp RL, Zajac AM: Veterinary Clinical Parasitology. Iowa, USA: University Press; 1994. 
124. Taylor MA, Coop RL, Wall RL: Veterinary Parasitology. Oxford: Blackwell Publishing; 2007

125. Venco L, Genchi M, Genchi C, Gatti D, Kramer L: Can heartworm prevalence in dogs be used as provisional data for assessing the prevalence of the infection in cats? Vet Parasitol 2011, 176:300-303.

126. Casiraghi M, Mazzocchi C, Mortarino M, Ottina E, Genchi C: A simple molecular method for discrimination common filarial nematodes of dogs (Canis familiaris). Vet Parasitol 2006, 141:368-372.

127. Rishniw M, Barr SC, Simpson KW, Frongillo MF, Franz M, Dominguez Alpizar $J \mathrm{~L}$ : Discrimination between six species of canine microfilariae by a single polymerase chain reaction. Vet Parasitol 2006, 135:303-314.

128. Oh HW, Jun HK, You MJ, Hayasaki M, Song KH: Ectopic migration of an adult heartworm in a dog with dirofilariasis (case report). Korean J Parasitol 2008, 46:171-173.

129. Megat Abd Rani PA, Irwin PJ, Gatne M, Coleman GT, Mclnnes LM, Traub RJ: A survey of canine filarial diseases of veterinary and public health significance in India. Parasit Vectors 2010, 3:30

130. Latrofa MS, Dantas-Torres F, Annoscia G, Genchi M, Traversa D, Otranto D: A duplex real-time polymerase chain reaction assay for the detection of and differentiation between Dirofilaria immitis and Dirofilaria repens in dogs and mosquitoes. Vet Parasitol 2012, 185:181-185.

131. Latrofa MS, Weigl S, Dantas-Torres F, Annoscia G, Traversa D, Brianti E, Otranto D: A multiplex PCR for the simultaneous detection of species of filarioids infesting dogs. Acta Trop 2012, 122(1):150-154.

doi:10.1186/1756-3305-6-16

Cite this article as: Otranto et al:: Vector-borne helminths of dogs and humans in Europe. Parasites \& Vectors 2013 6:16.

\section{Submit your next manuscript to BioMed Central and take full advantage of:}

- Convenient online submission

- Thorough peer review

- No space constraints or color figure charges

- Immediate publication on acceptance

- Inclusion in PubMed, CAS, Scopus and Google Scholar

- Research which is freely available for redistribution 